DOI 10.37882/2223-2982.2020.10.34

\title{
ОРГАНИЗАЦИОННО-ПРАВОВЫЕ ОСНОВАНИЯ ФОРМИРОВАНИЯ И РЕАЛИЗАЦИИ ЖИЛИЩНОЙ ПОЛИТИКИ В МОСКВЕ В 1953-1964 ГОДАХ
}

\section{ORGANIZATIONAL AND LEGAL BASIS FOR THE FORMATION AND IMPLEMENTATION OF HOUSING POLICY IN MOSCOW IN 1953-1964}

\section{Skripkin}

Summary: The article deals with topical aspects of one of the most significant periods in the history of the USSR, associated with the trends towards urbanization, urban planning of the thaw period, which made significant adjustments not only to the organizational and legal system of housing policy in Moscow in 1953-1964. The transition from the elite architecture of the "Stalinist Empire» to mass Soviet architecture is reflected in the period of the "Khrushchev thaw», which reflects not only the new prospects for the architectural appearance of Soviet cities, but also the socio-economic motives of political reforms taking place in the field of housing innovation. The considered legislative acts of the Soviet period, preceding and accompanying the implementation of a completely new system of housing urban development, are unique Chronicles of building the image of everyday life of Soviet citizens during the thaw. In historical analysis, the organizational and legal foundations of housing reforms laid by N. S. Khrushchev after coming to power are one of the important key factors in the formation of scientific and methodological trends in the architecture of the Soviet period.

Keywords: urban planning, housing construction, thaw, panel houses, Stalinist Empire.

\author{
Скрипкин Дмитрий Дмитриевич \\ Аспирант, Московский городской педагогический \\ университет \\ dimas-080594@rambler.ru
}

Аннотация: В статье рассматриваются актуальные аспекты одного из значимых периодов истории СССР, связанного с тенденциями к урбанизации, градостроительству периода оттепели, внесшего значительные коррективы не только организационно-правовую систему жилищной политики в Москве в 1953-1964 гг. Отражением процесса перехода от элитарной архитектуры «сталинского ампира» к массовой советской архитектуре является именно период «хрущевской оттепели», отражающий не только новые перспективы архитектурного облика советских городов, но и социально-экономические мотивы политических реформ, происходящих в сфере жилищным инновациям. Рассмотренные законодательные акты советского периода, предшествующие и сопровождающие реализацию совершенно новой системы жилищного градостроения, представляют собой уникальные хроники выстраивания образа повседневности жизни советских граждан в период оттепели. Организационно-правовые основы жилищных реформ, заложенные Н.С. Хрущевым после прихода к власти, в историческом анализе являются одним из важных ключевых факторов становления научных и методических тенденций архитектуры советского периода.

Ключевые слова: градостроительство, жилищное строительство, оттепель, панельные дома, сталинский ампир.
$\Pi$ ериод «хрущевской оттепели» в СССР является кардинальным во многих сферах жизнедеятельности, так как предполагал множество реформ, смену окружающей действительности в самых разных ракурсах. Особенно изменились градостроительные принципы, заложенные еще в сталинское время. Город представлялся в начале 50-х годов как некоторая система жилых массивов, и в данной разработке такая система предполагала и создание соответствующей инфраструктуры. Данный проект в своей идейной концепции отражал опыт архитекторов запада (идеи Ле Корбюзье), которые напрочь отрицали в сталинский период. Новая архитектура подразумевала не только определенные тенденции в градостроительстве, но и организационно-правовую основу, выделяющую образ жилого городского пространства, предлагающего комфортную жизнь для советских граждан. Такие архитектурные инновации являли собой значительный контраст между сталинскими застройками и хрущевскими домами, при этом данный контраст заключался не только в облике или идейном выражении, но и в совершенно разных подходах к строительству жилья. Новые жилищные формы были не просто отличием двух исторических периодов, но и становились объединяющими город, выражающие его цельность, снимающие барьеры с центра с великолепными сталинскими высотками и рядом существующей рабочей окраины с барачным типом жилья. И самый главный принцип нового жилищного реформирования это массовость, именно массовое жилищное строительство в СССР имело огромное значение не только в политическом смысле, но и фактическом обыденном, когда многие советские граждане не могли не только приобрести себе жилье, но и решить свои базовые потребности к комфорту. При этом, послевоенное население уве- 
личивалось и жить становилось просто негде, особенно в рамках отдельного жилья.

СССР стремительно решал задачу жилищного строительства, и достаточно активно, в актуальном реформировании только за 1950-1959 год смогли улучшить свои жилищные условия практически четверть всех жителей страны (около 54 миллионов человек).

Сравнение динамики переписи советского городского населения указывает на то, что к 1959 году в городах и селах проживало 208,8 миллионов граждан, тогда как через 3 года, цифра переписи указывала на 111,2 миллиона городских жителей против численности сельских - 108,6 миллионов. Впервые российская история зафиксировала факт превышения доли городских жителей над сельскими. Такая ситуация указывала на то, что необходимо было менять взгляды на решение жилищных вопросов в СССР, с учетом того, что промышленные предприятия расширялись, и жители сел, переезжая в город, работая на фабриках и заводах, становились городскими жителями, нуждающимися в жилье. Разрастание промышленности в городских масштабах стало не только экономическим фактором развития СССР, но и источником жилищной проблемы.

С начала 1950-х годов по 1965 год темпы развития советской экономики неуклонно росли. Так, производство после V пятилетки (1951-1955 годы) увеличилось на $85 \%$, за три года VI пятилетки - на $64 \%$, а за семилетку (1959 - 1965 гг.) - на 84\%.

В целом, проблема жилья не являлась новой для Советского Союза, исторически мы можем это проанализировать с помощью секретной справки от 18 августа 1953 года ЦСУ СССР Л. Кагановичу о состоянии городского жилого фонда в 1940-1952 годах. В 1928 году не хватало 100 млн квадратных метров по санитарным нормам для удовлетворения жилищных нужд советских граждан, в 1953 году - те же нормы указывают на нехватку 96 млн квадратных метров [9]. По сути, за 30 лет этого периода никак не изменилась ситуация с жильем, еще и добавилась проблема качества жилья. Бараки в составе общего городского жилого фонда представляли собой 18 млн квадратных метров, что указывало на то, что около 4 миллионов советских людей жили в бараках, не отвечающих требованиям санитарных норм, и являвшихся источниками социальных норм и деструктивного поведения населения. В целом, к 1953 году СССР стоял на пороге уже обоснованных реальным положением дел необходимых реформ жилищной политики.

Постановление ЦК КПСС и Совета министров СССР от 19 августа 1954 года, «О развитии производства сборных железобетонных конструкций и деталей для строитель- ства» [1] является одним из первых инициаций реализации принципа создания массового жилья. Расширение количества заводов предполагало создание множества рабочих мест, при этом учитывался тот фактор, что на заводы пойдет работать именно сельская молодежь, нуждающаяся в жилье.

В дальнейшем в осуществлении новой жилищной политики немаловажным оказалось Всесоюзное совещание архитекторов и строителей, которое проходило с 30 ноября по 7 декабря 1954 года. Именно на данном совещании Н.С. Хрущев осудил множество архитектурных традиций сталинского периода, в частности стиль «сталинский ампир» был признан «украшательством». Главные архитекторы страны (А. Мордвинов, А. Власов и др.) были названы виновниками распространения ненужной дороговизны, украшательских элементов и пропаганде данных архитектурных изысков. Основное направление Хрущева было в том, что строительство должно быть массовым, недорогим, быстростроящимся и многофункциональным благодаря одобрению типового проекта. Такое массовое жилье не уникально, зато позволяет расселить множество людей в отдельные квартиры, предоставить им тот комфорт, который по санитарным нормам будет основан на правовом проекте. На этом же собрании были применены и репрессивные меры ко многим архитекторам, получившим государственные награды именно за осуждаемые Хрущевым проекты в сталинский период [11]. Конечно, данные меры были приняты не только из-за критики архитектурного направления, они были созвучны всем будущим репрессиям в различных сферах при развенчивании «культа Сталина» как возможности модернизации всей политической системы, при этом не меняя ее основной сути.

Результатом совещания стало изменение вектора проектной архитектуры в сторону уменьшения пышности и богатства зданий, однако, общие формы и стилевое направление осталось прежним, что не могло не остаться незамеченным руководством страны. И 4 ноября 1955 года официально было принято Постановление «Об устранении излишеств в проектировании и строительстве»[3], положившее начало архитектурной реформе, полностью завершающей эпоху советского монументального классицизма. В стране начались множественные изменения, связанные с уже начатыми стройками или стройками в проекте. Строительство монументальных проектов было заморожено, проекты срочно дорабатывались, архитекторы следовали плану удешевления и удаления архитектурного декора в формате признанного излишества, там, где это технически дозволялось. В реализации процесса жилищной политики менялись архитектурные концепты, некоторые стройки смогли быть завершены только спустя несколько лет, по заново пересмотренным проектам. 
В 1954 году вышло несколько постановлений ЦК КПСС и Совета министров СССР, которые раскрывали основные пути индустриализации строительного производства, при этом большое внимание в них уделялось особенностям снижения стоимости строительства, также приводились доводы к совершенствованию деятельности проектных бюро, а также рассматривались организационно-правовые основы реформирования системы управления строительством и архитектурой.

Отметим, что агрессивные меры с архитектурными излишествами касались не только вышеописанных аспектов, но и касались жизни людей. Например, известный и награжденный Сталинской премией Е. Рыбицкий за проект «Дом работников МГБ» (1949) был раскритикован спустя 3 года за те же излишества в виде затратного декора и общей высокой стоимости дома (п.7 Постановления «Об устранении излишеств в проектировании и строительстве»), что привело к лишению премии в 1955 году [11].

В Постановлении «Об устранении излишеств в проектировании и строительстве» уточнялся момент того, что, «увлекаясь показной стороной, многие архитекторы занимаются главным образом украшением фасадов зданий, не работают над улучшением внутренней планировки и оборудования жилых домов и квартир, пренебрегают необходимостью создания удобств для населения, требованиями экономики и нормальной эксплуатации зданий»[3]. Более подробно описывалась ненужность различных башенных конструкций, декора, связанного со стилями прошлых веков, что приводило к превышению расходов при строительстве различных жилых и общественных зданий. Отдельно выражалось мнение о том, что такие затраты на «архитектурные излишества» привели к причине недостатка государственных средств для строительства жилья для трудового населения СССР.

По сути рассмотренное Постановление стало [3] стало началом конца монументальных традиций «сталинского ампира», и переформатировании философии советской архитектуры в различных аспектах, как в правовых, так и в практико-методологических. Изменилась концепция преподавания в архитектурных вузах, проводилась интеграция социально-политических взглядов руководства страны в практический аспект реализации нового архитектурного стиля, который вполне можно назвать социальным, так как направлен он был на осуществление массовой жилищной политики в части обеспечения всех советских граждан комфортными жилищными условиями.

31 июля 1957 года ЦК КПСС и Совет министров СССР приняли Постановление «О развитии жилищного строительства в СССР» [4].В данном документе отражались до- статочно четкие цели государства и ориентация на социальное жилье. Среди основных пунктов можно выделить следующие положения:

- «...исходить из необходимости ликвидации в ближайшие 10-12 лет недостатка в жилищах для трудящихся».

- «Начиная с 1958 года, в жилых домах, строящихся как в городах, так и в сельской местности, предусматривать экономичные благоустроенные квартиры для заселения одной семьей».

— «Ввести с 1 января 1959 года планирование и учёт жилищного строительства в квадратных метрах жилой и полезной площади и в количестве квартир»[4].

В целом, суть организационно-правовой организации жилищной политики СССР в середине 50-х-начало 60-х годов являла собой, практически впервые в советской истории, желание решения множества социальных проблем, источником которых был в том числе и недостаток жилья. В Постановлении «О развитии жилищного строительства в СССР» также акцентировался вопрос увеличения плана жилищного строительства на период VI пятилетки на 215 миллионов квадратных метров, что решило бы проблему жилья в СССР и позволило бы совершенствовать и развивать организацию системы жилищного градостроения в Москве и других советских городах.

В последствии Н.С. Хрущевым планка жилищной реформы была поднята еще выше, в программе VII пятилетки были показаны планы по увеличению жилищного строительства до 650-660 млн квадратных метров, расширяя границы городского градостроения к сельскому [7]. Организация жилищной политики в перспективе предполагала обеспеченность к 1965 году практически всех граждан СССР, в норме 6 квадратных метров жилой площади на человека, что несомненно являлось улучшением качества жизни населения, хотя и в неполной мере решала все жилищные проблемы москвичей.

В организационно-правовой основе такие жилищные реформы меняли саму суть московского градостроения, расширяли границы возможностей, корректировали архитектурный стиль. Для повышения сознательности и активности специалистов в этом направлении был организован Всесоюзный конкурс проекта Дворца Советов (1956 год), победителем которого стал А.А. Власов, в архитектурном замысле которого отсутствовали практически все элементы декорирования, его проект отличался простотой, которая легла в основу закладки стиля советского минимализма в архитектуре [6].

Поворотной точкой в истории жилищной реформы СССР, изменившей саму концепцию архитектурно-стро- 
ительного направления, стали Постановления «О мерах по дальнейшей индустриализации, улучшению качества и снижению стоимости строительства» 1956 года [2] и «О Развитии жилищного строительства в СССР» 1957 года [4].

Удешевление строительства жилья, ускорение сроков проектно-строительных работ, упрощение самого понятия жилого строительства - являлись основными целями разработки вышеуказанных правовых документов. Доступность жилья - это основной постулат советского правительства, который реализовался в полной мере в массовом жилом строительстве в период 19531964 гг.

На проводимом в 1959 году XXI съезде КПСС была отмечена еще не решенная проблема доступного жилья для трудящегося населения СССР, что позволило назвать ее «одной из важнейших задач» [10]. Упор на следующую пятилетку делался именно на то, что у каждой семьи отдельное жилье, что предполагало расселение коммунальных квартир, снос бараков, и доступность собственного жилья для коммунистической семьи.

Массовое жилье по типу панельных домов в историю вошло с названием «хрущевки», и представляло собой аналог немецких блочных зданий (Plattenbau) 1920-го года. Именно такие панельные блоки стали основой для более 13 тыс. домов за 10 лет хрущевской жилой реформы. Высота таких жилых домов ограничивалась 5 этажами без лифта, что также позволяло удешевить строительство. Соответствующей базой для производственного обеспечения массового строительства явилось увеличение количества заводской инфраструктуры, выпускающей блоки и железобетонные плиты, необходимые для стройки. С 1960 года было проведено увеличение проектов жилых домов до 9 этажей, а с 1963 года уже выстраивались жилые массивы в 12 этажей. Для Москвы и других советских городов это был просто жилищный прорыв, так как быстро строящееся жилье позволяло обеспечивать жилые нужды большего количества населения, прибывавшего в Москву и другие крупные города для работы.

Отметим, что производительность и обеспечение строительства железобетонными блоками позволяло ускорить и само строительство, так как по технологии сборка такого дома напоминала по инструкции проекта конструктор, исключающий трудоемкие процессы по типу установки арматуры, бетонирования. Декор ар- хитектурного плана практически отсутствовал, поэтому отделка зданий так же позволяла сэкономить время и деньги. В целом, специалисты, изучающие направление панельного строительства, выделяют несомненно преимущество именно в том, что массовый принцип полностью отражает результат в виде достижения цели строительства, удешевлении затрат на производство и строительные работы, на ускорение сроков реализации планов жилищной политики.

Конечно, дома панельного типа кроме преимуществ, имели и некоторые недостатки, выделенные также как самими строителями, так и жильцами таких домов:

- кухни в квартирах были очень маленькие, не соизмеримые с жилыми комнатами;

- коридоры и лестничные клетки были узкие и неудобные;

- низкие потолки,

- санитарные узлы были совмещены, что было явным недостатком, так как при норме 6 квадратов на человека жилой площади, в 1 квартире могло проживать от 3 и более человек;

- низкая шумозоляция панельных домов;

- нарушение теплоизоляционных систем [8].

Тем не менее, историками отмечается противоречивость рассматриваемой жилищной реформы, которая в целом в организационно-правовом плане была подготовлена практически безукоризненно. Отсутствовала уникальность, снизилась творческость в архитектурном деле, происходило обезличивание городского стиля Москвы. Система жилищного строительства, несмотря на социальную подоплёку улучшения жизни граждан, внедряла в советское мировоззрение казенность, усредненность и ощущение низкого качества жилья [7].

Несмотря на все принятые законотворческие документы, существовали и санитарные нормы, которые не могли полностью реализовать проекты «хрущевок» для многочисленных советских семей. Однако жилищная политика 1953-1964 годов позволила совершенно поиному взглянуть на социальные основы построения советского государства, исторически обосновав необходимость совершенствования организационно-правовых основ системы обеспечения жильем население Москвы и других городов СССР. Данная реформа оставила след в каждом городе Советского Союза, и, в какой-то мере решила проблему населения, которая одновременно была широко озвучена, но тем не менее терялась в монументальном строительстве советского классицизма. 


\section{ЛИТЕРАТУРА}

1. Постановление ЦК КПСС и Совета Министров СССР от 19 августа 1954 года N 1804 «0 развитии производства сборных железобетонных конструкций и деталей для строительства» // Правовые вопросы строительства в СССР. М.: Всесоюзный институт юридических наук, 1960. 261 с.

2. Постановление ЦК КПСС и Совета министров СССР от 23 августа 1955 года N 1548 «0 мерах по дальнейшей индустриализации, улучшению качества и снижению стоимости строительства»/Постановления ЦК КПСС и Совета Министров СССР по вопросам строительства от 23, 24 августа и 4 ноября 1955. М. Политиздат. 1955г. 176с.

3. Постановление ЦК КПСС и Совета Министров СССР 4 ноября 1955 г. N 1871 «0б устранении излишеств в проектировании и строительстве». М.: Госполитиздат, 1955. 14 с.

4. Постановление ЦК КПСС и Совета Министров СССР от 31 июля 1957 года N 931 «0 развитии жилищного строительства в СССР». М.: Госполитиздат, 1957. 22 c.

5. Горлов В.Н. Жилищное строительство в Москве как социокультурная проблема (1953-1991 гг.) / В.Н. Горлов. М.: Реглант, 2005. 499 с

6. Меерович М.Г. Принудительное изменение творческой направленности советской архитектуры в середине 1950-х годов / М.Г. Меерович // Архитектон: известия вузов. 2018. № 1 (61). С. 5.

7. Меерович М.Г. Хрущевская жилищная реформа в СССР: неизученные страницы истории / М.Г. Меерович // Фундаментальные, поисковые и прикладные исследования РААСН по научному обеспечению развития архитектуры, градостроительства и строительной отрасли Российской Федерации в 2015 году. Сборник научных трудов РААСН. Российская академия архитектуры и строительных наук. Москва, 2016. С. 297-301.

8. Меерович М.Г. Хрущевская перестройка творческой направленности советской архитектуры / М.Г. Меерович // Фундаментальные, поисковые и прикладные исследования РААСН по научному обеспечению развития архитектуры, градостроительства и строительной отрасли Российской Федерации в 2017 году. Сборник научных трудов Российской академии архитектуры и строительных наук. Москва, 2018. С. 112-121.

9. Огородникова 0.А. Массовое жилищное строительство в истории советской повседневности / 0.А. Огородникова // Universum: общественные науки. 2018. № 3 (44). C. 6-9.

10. Светличный Б. Неотложные задачи советского градостроительства / Б. Светличный // Архитектура СССР. 1954. № 11. С. 27-30.

11. Хмельницкий Д. Архитектура Сталина: психология и стиль / Д. Хмельницкий; ред. Е.П. Крюкова. М.: Прогресс-Традиция, 2007. 376 с.

12. Шквариков В. Основные вопросы планировки и застройки советских городов / В. Шквариков // Архитектура СССР. 1955. № 12. С. 7-14.

\section{(ㄷ Скрипкин Дмитрий Дмитриевич (dimas-080594@rambler.ru).}

Журнал «Современная наука: актуальные проблемы теории и практики»

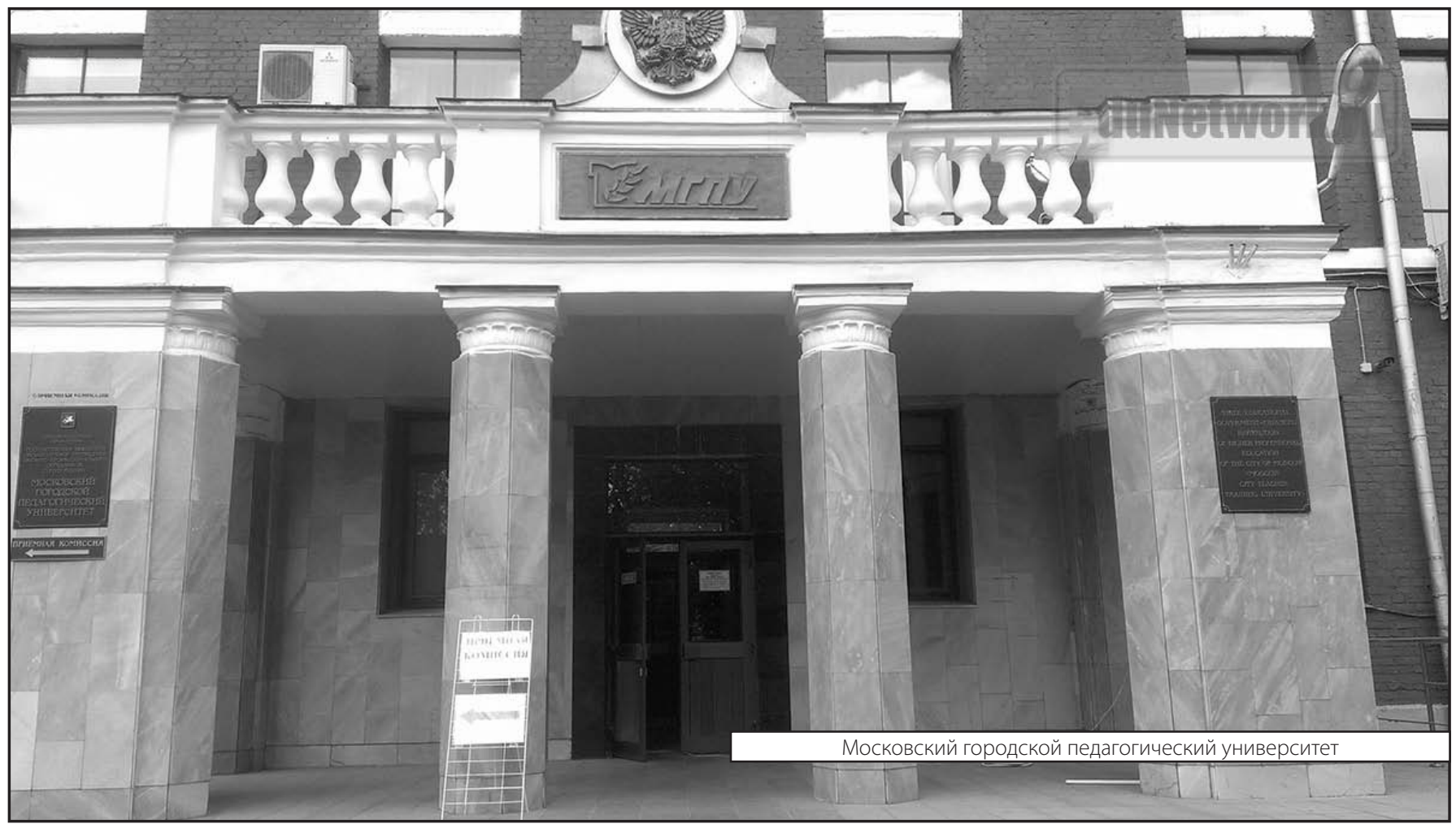

